\title{
The effects of core nucleus and cortical lesions in turtles on reversal and dimensional shifting
}

\author{
JACQUELYN CRANNEY and ALICE SCHADE POWERS \\ Bryn Mawr College, Bryn Mawr, Pennsylvania
}

\begin{abstract}
Turtles with lesions of the core nucleus of the dorsal ventricular ridge or of the cortex were studied on the postoperative acquisition of a series of visual discrimination problems, which involved reversals and shifts of dimension, from pattern to color and vice versa. The results showed a double dissociation between the effects of the two lesions. Turtles with core nucleus lesions were impaired on the initial problem, a pattern discrimination between horizontal and vertical stripes. Cortically lesioned turtles were not different from sham-lesioned animals on this problem, but they were impaired on pattern reversal, where turtles with core nucleus lesions were unimpaired. Both groups had deficits on a shift from color to pattern, which was a reversal of the initial pattern problem. Both groups performed normally on color discrimination. Turtles with lesions that damaged both the core nucleus and the cortex showed impairments that appeared to be a sum of the deficits caused by each lesion alone. The results are discussed in terms of their implications for our understanding of the evolution of visual function.
\end{abstract}

Recent anatomical research has shown that there are two parallel visual pathways from the retina to the telencephalon in each of the three amniotic classes: reptiles, birds, and mammals (Altman \& Carpenter, 1961; Balaban \& Ulinski, 1981; Cohen \& Karten, 1974; Diamond \& Hall, 1969; Hall \& Ebner, 1970a, 1970b, Nauta \& Karten, 1970; Schneider, 1969). These pathways have been called the thalamofugal and tectofugal pathways (Nauta \& Karten, 1970). They are summarized in Table 1. The thalamofugal pathway projects from the retina to the dorsal thalamus and from there to the telencephalon. The tectofugal pathway projects from the retina to the optic tectum, thence to a region of the dorsal thalamus, and finally to a region of the telencephalon. In both the thalamus and the telencephalon, the projection areas of the tectofugal and thalamofugal pathways are distinct. Figure 1 shows the telencephalic terminations of the two pathways in the painted turtle.

In all amniotes studied, lesions of the telencephalic termination of the tectofugal pathway disrupt visual discrimination performance on pattern discrimination (Cowey \& Gross, 1970; Killackey, Snyder, \& Diamond, 1971; Sprague, Levy, DiBerardino, \& Berlucchi, 1977) or on both pattern and visual intensity (Hodos \& Karten, 1970; Reiner \& Powers, in

A preliminary version of this research was presented at the meeting of the Society for Neuroscience held in Los Angeles in October 1981. This research was supported by NS-16688 to A.S.P. The able assistance of Kathryn Nelson, Jennifer Leeman, and William Grisham is gratefully acknowledged. Requests for reprints should be addressed to Alice S. Powers, Department of Psychology, Bryn Mawr College, Bryn Mawr, Pennsylvania 19010. press). Lesions of the telencephalic termination of the thalamofugal pathway have less consistent effects, ranging from no effect on pattern and visual intensity discriminations in birds and reptiles (Hodos, Karten, \& Bonbright, 1973; Reiner \& Powers, in press) to losses with recovery in rats, cats, and tree shrews (Berkeley \& Sprague, 1979; Hughes, 1977; Killackey et al., 1971; Sprague et al., 1977) and to profound losses in primates (Humphrey, 1970; Pasik \& Pasik, 1971).

Studies of the effects of brain lesions on more complex visual discrimination tasks, such as reversal of a previously learned discrimination or shifting from one stimulus dimension to another, have led to different results in different classes of amniotes. In mammals, lesions of the extrastriate or inferotemporal cortex, part of the tectofugal system, produce deficits on reversal (Killackey et al., 1971; Manning, 1972) and dimensional shift (Rothblat \& Wilson, 1969). While the effects of lesions of the thalamofugal pathway on such problems have not been much studied, there are two studies with tree shrews that suggest that striate cortex lesions do not affect reversal and dimensional shifting (Killackey et al., 1971; Killackey, Wilson, \& Diamond, 1972). In birds, the pattern of results is quite different. Pigeons with lesions in the thalamofugal system show no deficits on the original learning of a visual discrimination but do show deficits on its reversal (Powers, 1969; Stettner \& Schultz, 1967) or on a shift to another dimension (Powers, Halasz, \& Williams, 1982). It should be noted that in birds this effect does not seem to be limited to the visual modality: spatial reversals are also impaired (Macphail, 1971). Lesions of the tectofugal pathway in birds result in deficits 
Table 1

Anatomy of the Forebrain Visual Pathways in Amniotes

\begin{tabular}{|c|c|c|c|c|c|}
\hline \multirow[b]{2}{*}{ Species } & \multicolumn{2}{|c|}{ Thalamofugal System } & \multicolumn{3}{|c|}{ Tectofugal System } \\
\hline & $\begin{array}{c}\text { Retinal Termination } \\
\text { in Thalamus }\end{array}$ & $\begin{array}{l}\text { Projection to } \\
\text { Telencephalon }\end{array}$ & $\begin{array}{c}\text { Retinal Termination } \\
\text { in Midbrain }\end{array}$ & Thalamic Relay & $\begin{array}{l}\text { Projection to } \\
\text { Telencephalon }\end{array}$ \\
\hline $\begin{array}{l}\text { Turtle } \\
\text { (Hall \& Ebner, } \\
\text { 1970a, 1970b) }\end{array}$ & $\begin{array}{l}\text { Lateral geniculate } \\
\text { nucleus, pars } \\
\text { dorsalis }\end{array}$ & Dorsal Cortex & Optic Tectum & $\begin{array}{l}\text { Nucleus } \\
\text { Rotundus }\end{array}$ & $\begin{array}{l}\text { Core nucleus of } \\
\text { dorsal ventricu- } \\
\text { lar ridge }(\mathrm{CN})\end{array}$ \\
\hline $\begin{array}{l}\text { Pigeon } \\
\text { (Nauta \& Karten, } \\
1970)\end{array}$ & $\begin{array}{l}\text { Nu opticalis } \\
\text { principalis } \\
\text { thalami (OPT) }\end{array}$ & $\begin{array}{l}\text { Hyperstriatum } \\
\text { dorsale (HD) and } \\
\text { nucleus intercalatus } \\
\text { hyperstriatii } \\
\text { accessorii (IHA) }\end{array}$ & Optic Tectum & $\begin{array}{l}\text { Nucleus } \\
\text { Rotundus }\end{array}$ & Ectostriatum \\
\hline $\begin{array}{l}\text { Tree shrew } \\
\text { (Diamond, Snyder, } \\
\text { Jane, \& Hall, 1970) }\end{array}$ & $\begin{array}{l}\text { Lateral geniculate } \\
\text { nucleus, pars } \\
\text { dorsalis }\end{array}$ & $\begin{array}{l}\text { Striate cortex } \\
\text { (Area 17) }\end{array}$ & $\begin{array}{l}\text { Superior } \\
\text { colliculus }\end{array}$ & Pulvinar & $\begin{array}{l}\text { Extrastriate and } \\
\text { temporal cortex }\end{array}$ \\
\hline \multirow[t]{2}{*}{$\begin{array}{l}\text { Cat } \\
\text { (Niimi \& } \\
\text { Sprague, } \\
1970 \text { ) }\end{array}$} & $\begin{array}{l}\text { Laminar part of the } \\
\text { lateral geniculate } \\
\text { nucleus, pars dorsalis }\end{array}$ & $\begin{array}{l}\text { Areas } 17 \text { and } 18 \\
\text { of cortex }\end{array}$ & $\begin{array}{l}\text { Superior } \\
\text { colliculus }\end{array}$ & \multirow{2}{*}{$\begin{array}{l}\text { Medial pulvinar } \\
\text { nucleus (nucleus } \\
\text { lateralis } \\
\text { posterior) }\end{array}$} & \multirow{2}{*}{$\begin{array}{l}\text { Areas } 19,20, \\
\text { and lateral } \\
\text { suprasylvian area } \\
\text { of Clare-Bishop } \\
\text { in cortex }\end{array}$} \\
\hline & $\begin{array}{l}\text { Medial interlaminar } \\
\text { part of the dorso- } \\
\text { lateral geniculate } \\
\text { nucleus }\end{array}$ & $\begin{array}{l}\text { Areas } 18,19 \text { and } \\
\text { lateral suprasylvian } \\
\text { area of Clare-Bishop } \\
\text { in cortex }\end{array}$ & & & \\
\hline Rhesus monkey & $\begin{array}{l}\text { Lateral geniculate } \\
\text { nucleus, pars } \\
\text { dorsalis }\end{array}$ & $\begin{array}{l}\text { Striate cortex } \\
\text { (Area 17) }\end{array}$ & $\begin{array}{l}\text { Superior } \\
\text { colliculus }\end{array}$ & $\begin{array}{l}\text { Inferior pulvinar } \\
\text { (Benevento \& } \\
\text { Fallon, 1975) }\end{array}$ & $\begin{array}{l}\text { Areas } 18,19 \\
\text { of cortex } \\
\text { (Benevento \& } \\
\text { Rezak, 1976) } \\
\end{array}$ \\
\hline
\end{tabular}

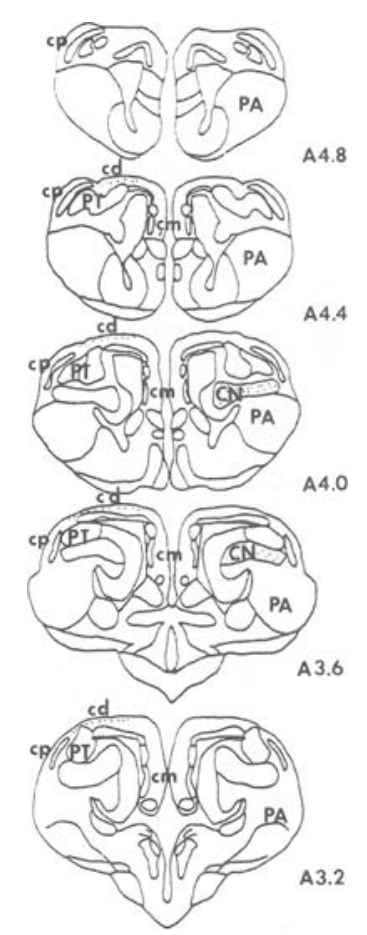

Figure 1. The terminations of the two visual projections to the telencephalon in turtles. The stipples on the left show the projection of the thalamofugal pathway to the dorsal cortex (cd). The stipples on the right show the projection of the tectofugal pathway to the core nucleus $(\mathrm{CN})$ of the dorsal ventricular ridge. The numbers on the sections refer to the anterior-posterior coordinates of the atlas of Powers and Reiner (1980). Other abbreviations: $\mathbf{c m}=$ medial cortex, $\mathbf{c p}=$ pyriform cortex, $\mathbf{P A}=$ paleostriatum augmentatum, $\mathbf{P T}=$ pallial thickening. on visual discriminations and on dimensional shift to another visual dimension (Powers et al., 1982); the effect on shifting may reflect only a difficulty in learning visual discriminations, rather than a deficit specific to shifting. No study of the effect of ectostriatal lesions on reversal learning has been done.

Thus, overall, it appears that deficits on reversal and dimensional shifting are produced by lesions of the tectofugal system in mammals and of the thalamofugal system in birds. Since the common ancestor of these two classes was a member of the ancient reptile order, the cotylosaurs, it seemed useful to study reversal and dimensional shifting in a living reptilian order closely related to the cotylosaurs, the Chelonia. In normal turtles, Graf and Tighe (1971) found that reversal was harder to learn than a dimensional shift, as is the case for other species as well (Mackintosh, 1974; Schade \& Bitterman, 1966).

The present study investigated the effects of lesions of the core nucleus $(\mathrm{CN})$ of the dorsal ventricular ridge and of the cortex on the learning of visual discriminations with a second dimension present but irrelevant, on dimensional shifting, and on reversal. Only one study of the effects of telencephalic lesions on reversals has been reported for reptiles. Peterson (1980) found deficits on spatial reversals (but not on the original discrimination) in lizards with lesions of the dorsal cortex. No studies have been done on the effects of lesions of the telencephalic visual areas of turtles on complex visual learning.

On simple visual discriminations, turtles with $\mathrm{CN}$ and cortical lesions show results similar to those 
found in birds (Reiner \& Powers, in press): that is, they have deficits with lesions of the telencephalic region of the tectofugal system but not with that of the thalamofugal system. On this basis, it was predicted that the pattern of results found on reversal and dimensional shifting would be more similar to those found in birds than to those found in mammals: that is, that core nucleus lesions would impair the learning of the first problem and perhaps subsequent ones, while cortical lesions would impair only the learning of reversals and shifts.

\section{METHOD}

\section{Subjects}

Twenty-two naive eastern and western painted turtles (Chrysemys picta), both male and female, were used. The turtles were fullgrown adults, $10-15 \mathrm{~cm}$ in carapace length and 200-400 g in weight. Subjects were maintained in individual open aquaria in a room with a controlled temperature set at $30^{\circ} \mathrm{C}$. An artificial day-night cycle, consisting of $14 \mathrm{~h}$ light and $10 \mathrm{~h}$ darkness, was controlled automatically. The aquaria were illuminated with ultraviolet light for $4 \mathrm{~h}$ each day.

\begin{abstract}
Apparatus
The apparatus consisted of a watertight black Plexiglas enclosure, with a hinged top. A houselight provided a general illumination of $64.8 \mathrm{~lx}$, measured in the center of the floor of the chamber with a Simpson illumination meter (Model 408). Centrally located on the front wall of the chamber was a translucent disk, whose center was $7 \mathrm{~cm}$ above the floor of the chamber. Food reward (Gerber's baby beef) was delivered through an aperture in the center of the disk with the aid of a food delivery system consisting of a surgical rubber hose attached to a syringe, whose plunger was driven by a Davis LR-130 liquid pump. Flanking this food magazine were two response keys, each a transparent plastic disk, $2.5 \mathrm{~cm}$ in diameter, through which stimuli could be presented to the turtle inside the chamber via rear-mounted IEE projectors. Depressions of the response key were relayed to standard programming equipment that controlled and recorded the events in the experimental chamber. The stimuli were $2.5 \mathrm{~cm}$ in diameter and were produced by illuminating two bulbs in each projector simultaneously. Each consisted of three white lines, $2 \mathrm{~mm}$ wide and separated by $3 \mathrm{~mm}$ from one another, on a colored background. The lines were either horizontal or vertical, and the background was either green or red. The intensity of the red key with lines superimposed was greater than that for the green (10.8 vs. $\left.5.4 \mathrm{~cd} / \mathrm{m}^{2}\right)$.
\end{abstract}

\section{Procedure}

Throughout behavioral training sessions, turtles received only one training session per day, consisting of 20 reinforcements. Each reinforcement consisted of the delivery of $.3 \mathrm{ml}$ of Gerber's baby beef and was accompanied by a $15-\mathrm{sec}$ illumination of the food magazine. During a training session, the chamber was illuminated by a houselight and was filled to a depth of $2.5 \mathrm{~cm}$ with water.

Preoperative training. There were two phases: food magazine training and key training. During magazine training, food reward was delivered on a variable time (VT) 90 -sec schedule. Within 3 to 10 sessions of magazine training, turtles had generally come to approach and eat from the food magazine whenever a reinforcement occurred. The turtles were then shifted to key training, during which reinforcement was made contingent on a displacement of the response key. During key training, a stimulus consisting of an evenly illuminated spot of white light was presented through one response key. The turtle was required to respond to that response key. Initially, the training stimulus was presented on either the right or left response key for all 20 trials of a session. Responses on the darkened key had no effect. The intertrial interval (ITI) was $15 \mathrm{sec}$. The positive key was changed from session to session until the turtles responded to the illuminated key at a steady rate (20 trials in $30 \mathrm{~min}$ or less). The white stimulus was then randomly and equally presented on each side, and the response requirement increased to a fixed ratio (FR) of 2 . Surgery was usually performed within 3 days after criterion (20 trials in less than $30 \mathrm{~min}$ ) was achieved on the FR 2 training.

Surgery. Twelve turtles received electrolytic lesions aimed at the CN. Coordinates were obtained from the stereotaxic atlas of Powers and Reiner (1980). Target coordinates were restricted to the portion of the $\mathrm{CN}$ at or anterior to the anterior commissure, that is, that portion of the $\mathrm{CN}$ in receipt of input from nucleus rotundus (Balaban \& Ulinski, 1981; Hall \& Ebner, 1970b). Turtles were anesthetized with Equithesin (im; dose, $.20 \mathrm{ml} / 100 \mathrm{~g}$ body weight). The skull was opened with a dentral drill, and the lesions were made electrolytically by passing a $2.0-\mathrm{mA}$ anodal current for $20 \mathrm{sec}$. Electrodes were standard size 0 insect pins, insulated with Formvar, except for $.5 \mathrm{~mm}$ at the tip. All lesions were made bilaterally. Since the $\mathrm{CN}$ is an extensive structure, two lesions (separated by $.5 \mathrm{~mm}$ ) were placed in the $\mathrm{CN}$ of each hemisphere. Five turtles received sham lesions in which the electrode was placed at the target areas but no current was passed. Four turtles received aspiration lesions aimed at the dorsal cortex while under Equithesin anesthesia. An attempt was made to aspirate only that portion of the dorsal cortex shown by Orrego (1961) to display visually evoked potentials. All cortical lesions were made bilaterally. One turtle received a sham lesion in which the dorsal cortex was exposed but no tissue aspirated. Five days of recovery from surgery were given before postoperative training began.

Postoperative training. All turtles were given a series of 10 visual discrimination problems in sequence. On each problem, two dimensions were present, pattern (horizontal vs. vertical stripes) and color (red vs. green), one relevant and the other irrelevant. The correct choice for each of the 10 problems is presented in $\mathrm{Ta}$ ble 2. Problem 1 yielded data on discrimination with an irrelevant dimension present. Problems 6 and 8 were reversals of Problems 5 and 7 , respectively. The rest of the problems involved shifts in dimensions from color to pattern, or vice versa.

As can be seen from Table 2, the first problem for all turtles was horizontal-positive. In this problem, pattern was relevant and color was irrelevant. On one kind of trial, the two keys were illuminated so that one had white horizontal stripes on a red background and the other had white vertical stripes on a green background. On another type of trial, horizontal stripes would appear on a green background and vertical on red. The position-left or right-of the positive stimulus was counterbalanced, so that there were four kinds of stimulus trials (each presented five times in a random fashion in each session). Since horizontal was correct in this problem, the turtle had to learn to choose the key containing horizontal stripes regardless of its color and regardless of which side it was on. The turtles were run on this problem until they reached criterion ( $85 \%$ correct on one day), when they were shifted to another problem, red positive. Again, they were trained

Table 2

The Correct Choice for Each of the Ten Discrimination Problems

\begin{tabular}{cccccccccc}
\hline \multicolumn{10}{c}{ Problem } \\
\hline 1 & 2 & 3 & 4 & 5 & 6 & 7 & 8 & 9 & 10 \\
\hline $\mathrm{H}+$ & $\mathrm{R}+$ & $\mathrm{V}+$ & $\mathrm{G}+$ & $\mathrm{V}+$ & $\mathrm{H}+$ & $\mathrm{G}+$ & $\mathrm{R}+$ & $\mathrm{H}+$ & $\mathrm{R}+$ \\
\hline
\end{tabular}

Note $-H_{+}^{+}=$horizontal stripe; $V+=$ vertical stripe; $R+=$ red; $G^{+}=$green. Problem 1 yielded data on discrimination with an irrelevant dimension present. Problems 6 and 8 were reversals of Problems 5 and 7, respectively. The rest of the problems involved shifts in dimension. 
to criterion. After reaching criterion, they were shifted again, and this sequence continued until the animals had completed all 10 problems.

In each of the 20-trial sessions, there was an intertrial interval of $15 \mathrm{sec}$, and reinforcement (or time out) was delivered on an FR 2 schedule (fixed ratio of 2 responses to 1 reinforcement). Correct response was followed immediately by the delivery of reinforcement at the magazine, which was illuminated for $15 \mathrm{sec}$ before the intertrial interval began again. An incorrect response was followed by a 30-sec time-out, in which both keys were dark. After a time-out, the same trial was repeated. Five repetitions of the trial were given, and if the turtle still had not chosen correctly, it was guided to the correct side by illuminating only the correct target. Thus, each trial ended with reinforcement (limited correction method). Both initial and repetitive errors were recorded, but the data presented below are for initial errors only.

Histology. Following postoperative training, turtles were anesthetized and perfused via the innominate artery with saline followed by Heidenhain's solution (without mercuric chloride). After several days of fixation in $10 \%$ Formalin, the brains were blocked, washed, dehydrated through graded alcohols, cleaned in toluene and embedded in paraffin. The brains were then sectioned at $15 \mu \mathrm{m}$ on a rotary microtome, mounted on slides, and stained by the Kluver-Barrera method (a luxol fast blue stain for fibres and a cresyl violet counterstain for cells). The lesions were reconstructed on standard sections from the atlas of Powers and Reiner (1980).

\section{RESULTS}

\section{Histology}

The percent damage to the $\mathrm{CN}$, dorsal cortex, pallial thickening, pyriform cortex, and medial cortex on each side of the brain was calculated. Animals with at least $20 \%$ damage to the $\mathrm{CN}$ on each side and with less than $10 \%$ damage on either side to any cortical structure were classified in the $\mathrm{CN}$ group. Animals with bilateral damage to the dorsal cortex and who had less than $10 \%$ damage to the $\mathrm{CN}$ on either side were classified in the Dorsal Cortex group. Two animals had substantial damage to the pyriform cortex, and little or unilateral damage to the dorsal cortex or CN. These animals were classified as the Pyriform Cortex group. Animals with over 10\% damage on each side to both $\mathrm{CN}$ and cortex (either pyriform or dorsal) were categorized as both $\mathrm{CN}$ - and cortexlesioned and put in the Both group. Representative lesions in these four groups are shown in Figures 2, 3,4 , and 5 . The nucleus rotundus in the thalamus was examined for retrograde degeneration, which would have occurred only if the lateral forebrain bundle had been severed. No such degeneration was found.

\section{Behavior}

Inspection of the data from the two cortically lesioned groups revealed that the performance of the two groups was similar across all problems. This is understandable, because the pyriform and dorsal cortices are highly interconnected (Desan, 1981). In subsequent analysis, therefore, the two cortical groups will be combined as the Cortex group.
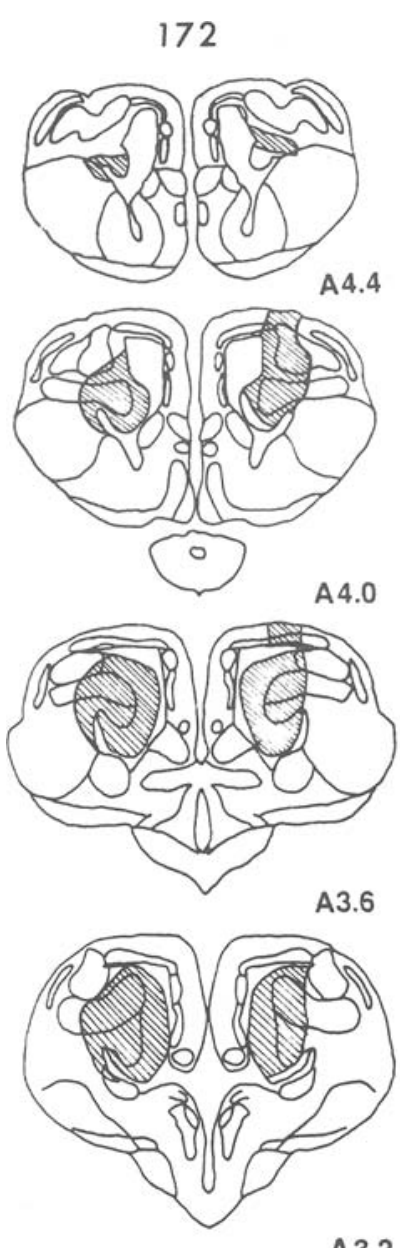

A3.2

Figure 2. The lesion of turtle No. 172, which had a lesion of the $\mathbf{C N}$.

Figure 6 presents the median initial errors for each group on the 10 problems. Error rates for the Sham group on the color problems were all low and became progressively lower, with the exception of the slight increase in errors on the color reversal (Problem 8). On pattern, the poorest performances by the Sham group were on Problem $1(\mathrm{H}+)$, Problem $3(\mathrm{~V}+)$, and Problem $6(\mathrm{H}+)$. Problems 3 and 6 were both reversals of the previous pattern problem: Problem 3 was a reversal in a dimensional shift, whereas Problem 6 was a direct reversal. The lesioned turtles, too, had the most difficulty with Problems 1, 3, and 6, but the CN group made more errors than the Sham group only on Problems 1 and 3, while the Cortex group made more errors than the Sham group only on Problems 3 and 6. The Both group appeared to make more errors than shams on all three problems. ${ }^{1}$

Performance deficits of the lesioned groups, as compared with the Sham group, were assessed by Mann-Whitney U tests (with $\alpha$ set at 0.02 , a partial 


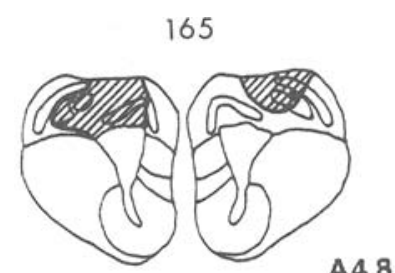

A4.8

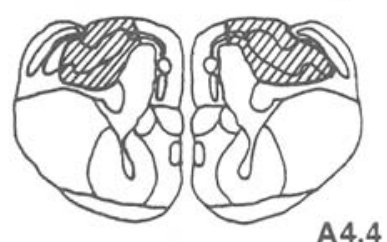

A4.4
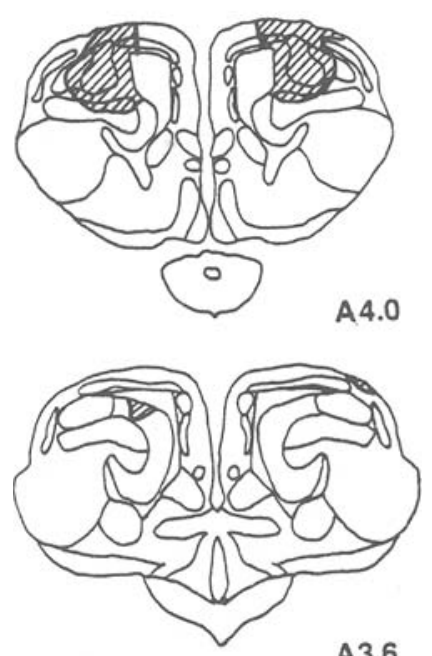

A3.6

Figure 3. The lesion of turtle No. 165, which had a lesion of the dorsal cortex and pallial thickening.

compensation for Type I experimentwise error). On the first problem, $\mathrm{CN}$ animals had significantly greater errors than did Shams $(U=0, p<.005)$. Performance of the Cortex and Both groups did not differ from that of the Sham group (Cortex, $U=20$, $p>.02$; Both, $U=7, p>.02$ ). Although the Both group appears to have a deficit, the difference was not significant, since one animal (No. 198) had a very low score. On the third problem, a reversal of Problem 1 and a shift to pattern from color, all three lesioned groups showed deficits $(U=2$ for $C N$ vs. Sham, $p<.01 ; U=6$ for Cortex vs. Sham, $p<.02$; $U=2$ for Both vs. Sham, $p<.02)$. The Cortex ( $U=$ $4, p<.01)$ and Both $(U=0, p<.01)$ groups showed deficits on the pattern reversal (Problem 6); there was no deficit for the $\mathrm{CN}$ animals $(\mathrm{U}=4, \mathrm{p}>.02)$.

Spearman rank-order correlations between errors on Problems 1 and 6, and percent damage to the $\mathrm{CN}$ or the cortex were calculated, using the data of all the lesioned animals. The correlations between $\mathrm{CN}$ damage and Problem 1 errors $(\varrho=0.61, p<.05)$ and between cortex damage and Problem 6 errors $(\varrho=$
$0.52, \mathrm{p}<.05)$ were significant and thus supportive of the results based on group data reported above. Correlations between $\mathrm{CN}$ damage and Problem 6 errors $(\varrho=.18)$ and between cortex damage and Problem 1 errors $(\varrho=.04)$ were not significant $(p>$ $.05)$. Correlations between errors on Problem 3 and damage to either $\mathrm{CN}$ or cortex were not expected to be significant, as the differential and interacting contributions of $\mathrm{CN}$ and cortical damage would not be taken into account. Damage to the pallial thickening did not correlate with errors on any of the three problems. There were no significant correlations $(p>.05)$ between total amount of damage to the brain and errors on Problem $1(\varrho=.45)$, Problem $3(\varrho=.11)$, or Problem $6(\varrho=.30)$.

\section{DISCUSSION}

The results of this experiment clearly showed that lesions of the $\mathrm{CN}$ in turtles produced a deficit on the postoperative acquisition of a pattern discrimination (Problem 1) and on a dimensional shift to pattern (Problem 3), but did not impair the learning of color discrimination. These data strongly support the idea

\section{2}

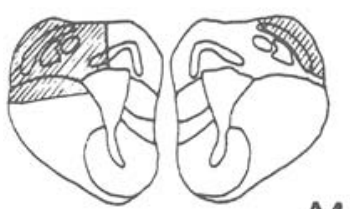

A4.8

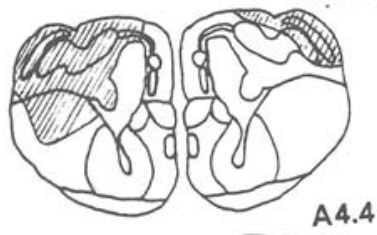

A 4.4
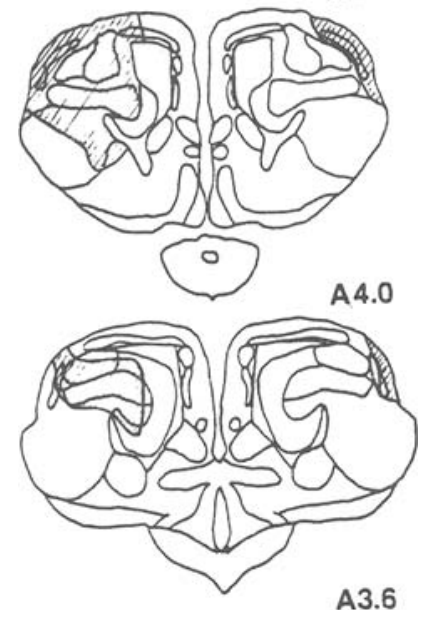

Figure 4. The lesion of turtle No. 142, which had a lesion of the pyriform cortex. This subject had unilateral damage to the $\mathrm{CN}$. 


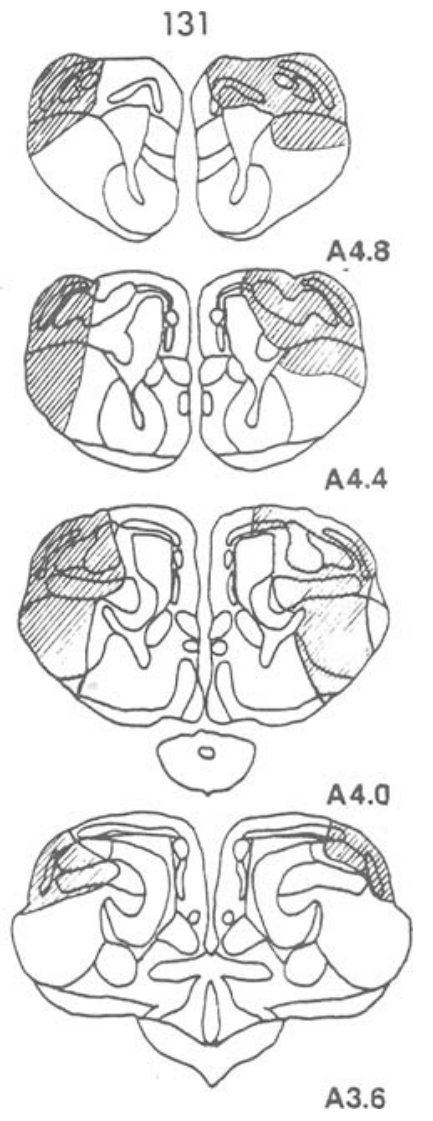

Figure 5. The lesion of turtle No. 131, a representative lesion of both the $\mathrm{CN}$ and cortex.

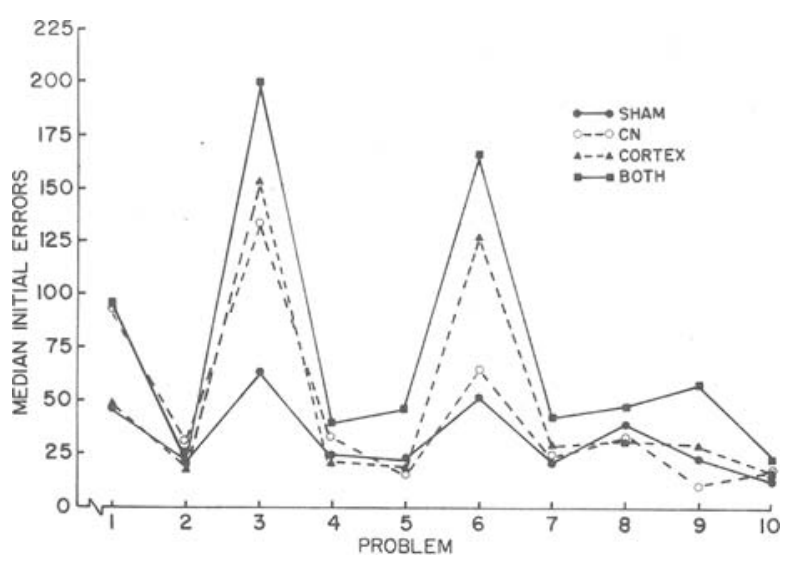

Figure 6. The median initial errors per problem for each of the four groups.

that $\mathrm{CN}$ lesions produce a deficit specific to visual pattern-discrimination ability, not a generalized loss that would impair the learning of any problem. Reiner and Powers (in press) found a deficit on retention of pattern and intensity discriminations after $\mathrm{CN}$ le- sions; this study is the first to show a similar deficit on acquisition. Furthermore, this study provided evidence that turtles with $\mathrm{CN}$ lesions eventually recovered from their deficit; by the third pattern problem (Problem 5), their performance was equivalent to that of the Shams.

As the lesions of the dorsal cortex were very small, the data on the effects of dorsal cortex lesions can only be considered suggestive. For this group, there was no deficit on the first problem, but there were deficits on the first dimensional shift to pattern (Problem 3), which was a reversal of the first pattern problem, and on the pattern reversal (Problem 6). The lack of an effect on Problem 1 is consistent with our previous finding that turtles with dorsal cortex lesions show no deficit on retention of pattern-discrimination learning (Reiner \& Powers, in press). It appears that cortically lesioned turtles are impaired on reversal of a pattern discrimination but not on the original learning of such a discrimination.

These conclusions are supported by the results of the Both group, which showed deficits on Problems 1, 3, and 6. Thus, they showed the effects of the $\mathrm{CN}$ lesions on Problems 1 and 3 and the effects of the cortical lesions on Problems 3 and 6. Appropriately the deficit of the Both group on Problem 3 appeared to be greater than that for either of the other two lesioned groups, suggesting that the effects of the two lesions summated in the performance of the Both group.

The performance of the sham animals in this experiment was similar to that found in other species (Schade \& Bitterman, 1966). For color, reversal was more difficult than dimensional shifting; the highest number of median errors on a color problem was on Problem 8, the color reversal. Shifting to the stimulus that was negative the last time color was relevant was more difficult than shifting to the same color that was correct the last time. In the terms used by Schade and Bitterman, the D- shift was more difficult than the $D+$ (median errors on Problem $4=24.5$ vs. median errors on Problem $10=13.5$ ). For pattern, reversal was slightly easier than the D- shift (the median number of errors for Problem $3=63.5$, and for Problem $6=52.5$ ). Both were more difficult than the D+ shift (Problem 5 $=22.5$ errors).

Graf and Tighe (1971) studied the relative difficulty of reversal and dimensional shifting in turtles and found that, in solving the dimensional shift problems, the animals treated each type of trial separately and learned to reverse their choice on trials in which that was required, while making few, if any, errors on trials in which the choice was unchanged. We found evidence of this sort of solution in our turtles' performance on shift problems, although the differences were not so marked as those found by Graf and Tighe. Their turtles made no errors on the 
unchanged subproblems, while ours made fewer than $20 \%$ of their errors on the unchanged trials. This pattern of responding is not surprising if the turtle is responding on the basis of the previous problem. It does not necessarily imply that each subproblem is being treated separately. There were no differences among the lesioned groups in their patterns of responding to the subproblems.

It is interesting to speculate on the nature of the deficits found with $\mathrm{CN}$ lesions. These lesions seemed to produce difficulty in solving pattern discriminations early in the series of problems. The pattern of responding, as revealed by a within-problem analysis, was similar to that of the sham-lesioned turtles in the early sessions. The $\mathrm{CN}$-lesioned turtles did not perseverate or respond at chance more than did the shams. The difference in responding came in the later stages of the discrimination learning, when the lesioned subjects took longer to achieve criterion than did the shams. The $\mathrm{CN}$ impairment may be a sensory one, an impairment in visual acuity. The $\mathrm{CN}$-lesioned subjects in the present experiment may not have been able to see the pattern stimuli well, if they could see them at all. If they had difficulty discerning the differences in stripe orientation, then they would take longer to learn this discrimination. Indeed, it is possible that they learned it by adopting some new strategy, such as attending to local differences in intensity. When color was made relevant, they had no difficulty in learning the discrimination, but when pattern was relevant again on Problem 3 it again took the $\mathrm{CN}$-lesioned subjects longer than it did the shams to master the problem. After mastering both horizontal-positive and vertical-positive problems, the $\mathrm{CN}$-lesioned subjects did not have any further difficulty on pattern problems, presumably because they had learned a strategy for solving them.

Several findings are consistent with our notion that $\mathrm{CN}$ lesions produce deficits in acuity. First, we have recently determined that $\mathrm{CN}$ lesions do not produce elevations of visual intensity-difference thresholds (Grisham \& Powers, 1982). Second, turtles with lesions of the $\mathrm{CN}$ are unimpaired on spatial discriminations (Grisham \& Powers, Note 1). There is one finding that may not initially appear to fit the hypothesis: Dunser, Fulbrook, Granda, and Maxwell (1980) reported large receptive fields in units of the dorsal ventricular ridge, and these large receptive fields might not appear to be adequate for processing the detailed spatial information needed for acuity discrimination. In pigeons, however, Macko and Hodos (1979) found elevations in acuity threshold after lesions of nucleus rotundus, which also has been reported to contain units with large receptive fields (Revzin, 1970). They concluded that "wide receptive field neurons are capable of processing detailed spatial information." To test more directly the notion that $\mathrm{CN}$ lesions produce acuity deficits, an experiment on acuity difference thresholds in turtles with $\mathrm{CN}$ lesions is currently being planned.

The results of this experiment are consistent with those found in birds and rather different from those found in mammals. In pigeons with lesions of the ectostriatum, which is the anatomical equivalent of the CN (see Table 1), there is a deficit on initial learning of a pattern or color discrimination and on a subsequent dimensional shift (Powers et al., 1982). Thus, the behavior of pigeons with ectostriatal lesions resembles that of turtles with lesions of the $\mathrm{CN}$, except that they show an impairment on color as well. Pigeons with lesions of the Wulst, the anatomical equivalent of the dorsal cortex of turtles (see Table 1), show deficits on visual and spatial reversal learning (Macphail, 1971; Powers, 1969; Stettner \& Schultz, 1967) and on a dimensional shift from color to pattern (Powers et al., 1982). Thus, again, there is a similarity between the results for birds and for reptiles.

In tree shrews, Killackey et al. (1972) found that lesions of the striate cortex, layer IV of which is anatomically similar to the dorsal cortex of turtles (see Table 1), produced deficits on the learning of a pattern discrimination with color irrelevant but not on a subsequent color discrimination and not on shifts of dimension between pattern and color. Their deficit, therefore, was more similar to that of the $\mathrm{CN}$-lesioned turtles in this experiment than to that of the cortically lesioned turtles. Like some of our CN subjects, their striate-lesioned subjects required remedial training on pattern discrimination. On the other hand, tree shrews with lesions of the temporal cortex, part of which is anatomically equivalent to the $\mathrm{CN}$ of turtles, had deficits on the original learning of a pattern discrimination with color irrelevant and showed continued difficulty on shifting dimensions throughout the series of problems. Subsequently, they also showed little improvement in reversal of a pattern discrimination, as compared with normal subjects. Thus, after temporal lesions in tree shrews, the deficit is similar to that found with cortical lesions in turtles in that both lesions seem to affect visual reversal learning. The effects are not identical, however, since, in turtles, cortical lesions do not produce a deficit on the initial problem. Moreover, in a study by Killackey et al. (1971), one tree shrew with a lesion of the temporal cortex was run on a position reversal and showed no impairment. In turtles, there may be a deficit on position reversal, since such a deficit has been found in lizards (Peterson, 1980).

It is not easy to understand how the two telencephalic visual structures in turtles, with their discrete functions, could have evolved into those found in tree shrews, in which the functions are almost the reverse. It would be useful, of course, to know 
how the cortical subdivisions function in insectivores, which are similar to the ancestral forms that gave rise to tree shrews. Unfortunately, no data on reversals or dimensional shifts are available for insectivores.

Our own speculation on the evolution of cortical visual structures follows that of Masterton and Glendenning (1978). In the ancestral reptiles, as in modern turtles, visual functions were mediated by the tectofugal system. The thalamofugal system did not have a function specific to vision but had, rather, a generalized function perhaps related to changing performance in the face of changed external situations. In the course of the evolution of mammals, the tectofugal system lost some of its visual function and became rather rudimentary as a result of the nocturnal habits of the early mammals (Polyak, 1957 , p. 869). When the ruling reptiles died out and mammals began to occupy diurnal niches, the geniculostriate system grew larger, lost its generalized functions (perhaps to the hippocampus), and took on some of the functions that had been mediated by the tectofugal system, specifically those having to do with attending to the relevant features of a visual stimulus. Visual pattern discrimination continued to be mediated by the tectofugal system. It may be that reversal and shifting of visual patterns are impaired by damage to that system largely because pattern vision itself is impaired.

Whether this analysis is viable depends to a great extent on increased understanding of these two telencephalic areas in reptiles and mammals. The current study confirmed our hypothesis that telencephalic visual functioning in turtles is more similar to that in birds than to that in mammals, and in future research we expect to find that, in turtles, $\mathrm{CN}$ lesions, but not cortical lesions, will affect acuity thresholds.

\section{REFERENCE NOTE}

1. Grisham, W. E., \& Powers, A. S. The effects of telencephalic lesions on spatial discrimination in turtles (Chrysemys picta). Unpublished manuscript, Bryn Mawr College, 1982.

\section{REFERENCES}

Altman, J., \& Carpenter, M. B. Fiber projections of the superior colliculus in the cat. Journal of Comparative Neurology, 1961, 116, 157-178.

Balaban, C. D., \& Ulinski, P. S. Organization of thalamic afferents to anterior dorsal ventricular ridge in turtles. I. Projections of thalamic nuclei. Journal of Comparative Neurology, 1981, 200, 95-129.

Benevento, L. A., \& Fallon, J. H. The ascending projections of the superior colliculus in the rhesus monkey (Macaca mulatta). Journal of Comparative Neurology, 1975, 160, 339-362.

Benevento, L. A., \& RezaK, M. The cortical projections of the inferior pulvinar and adjacent lateral pulvinar in the rhesus monkey (Macaca mulatta): An autoradiographic study. Brain Research, 1976, 108, 1-24.
Berkeley, M. A., \& Sprague, J. M. Striate cortex and visual acuity functions in the cat. Journal of Comparative Neurology, 1979, 187, 679-702.

Cohen, D. H., \& Karten, H. J. The structural organization of avian brain: An overview. In I. J. Goodman \& M. W. Schein (Eds.), Birds: Brain and behavior. New York: Academic Press, 1974.

Cowey, A., \& Gross, C. G. Effects of foveal prestriate and inferotemporal lesions on visual discrimination by rhesus monkeys. Experimental Brain Research, 1970, 11, 128-144.

Desan, P. Connections of cerebral cortex in the turtle (Pseudemys scripta elegans). Society for Neuroscience Abstracts, 1981, 7, 85. (Abstract)

Diamond, I. T., \& Hall, W. C. Evolution of neocortex. Science, 1969, 164, 251-262.

Diamond, I. T., Snyder, M., Killackey, H., Jane, J., \& Hall, W. C. Thalamocortical projections in the tree shrew (Tupaia glis). Journal of Comparative Neurology, 1970, 139, 273-306.

Dunser, K. R., Fulbrook, J. E., Granda, A. M., \& Maxwell, J. H. Functional properties of cells in the dorsal ventricular ridge of turtle (Pseudemys). Society for Neuroscience Abstracts, $1980,6,839$.

Graf, V., \& Tighe, T. Subproblem analysis of discrimination shift learning in the turtle (Chrysemys picta picta). Psychonomic Science, 1971, 25, 257-259.

Grisham, W. E., \& Powers, A. S. Effects of lesions of the core nucleus on visual intensity difference thresholds in turtles. Neuroscience Abstracts, 1982, 8, 207.

HALL, W. C., \& EBNER, F. F. Thalamotelencephalic projections in the turtle (Pseudemys scripta). Journal of Comparative Neurology, 1970, 140, 101-122. (a)

HALL, W. C., \& Ebner, F. F. Parallels in the visual afferent projections of the thalamus in the hedgehog (Paraechinus hypomelas) and the turtle (Pseudemys scripta). Brain, Behavior and Evolution, 1970, 3, 135-154. (b)

Hodos, W., \& Karten, H. J. Visual intensity and pattern discrimination deficits after lesions of ectostriatum in pigeons. Journal of Comparative Neurology, 1970, 140, 53-68.

Hodos, W., Karten, H. J., \& Bonbright, J. C. JR. Visual intensity and pattern discrimination after lesions of the thalamofugal visual pathway in pigeons. Journal of Comparative Neurology, 1973, 148, 447-468.

Hughes, H. Anatomical and neurobehavioral investigations concerning the thalamocortical organization of the rat's visual system. Journal of Comparative Neurology, 1977, 175, 311-336.

HumphreY, N. K. What the frog's eye tells the monkey's brain. Brain, Behavior and Evolution, 1970, 3, 324-337.

Killackey, H., Snyder, M., \& Diamond, I. T. Function of striate and temporal cortex in the tree shrew. Journal of Comparative and Physiological Psychology Monograph, 1971, 74(1, Pt. 2).

Killackey, H., Wilson, M., \& Diamond, I. T. Further studies of the striate and extrastriate visual cortex in the tree shrew. Journal of Comparative and Physiological Psychology, 1972, 81, 45-63.

Mackintosh, N. J. The psychology of animal learning. New York: Academic Press, 1974.

Macko, K. A., \& Hodos, W. Near-field visual acuity in pigeons following lesions of thalamic visual nuclei. Society for Neuroscience Abstracts, 1979, 5, 144.

MacPhaIL, E. M. Hyperstriatal lesions in pigeons: Effects on response inhibition, behavioral contrast, and reversal learning. Journal of Comparative and Physiological Psychology, 1971, 75, 500-507.

Manning, F. J. Serial reversal learning by monkeys with inferotemporal or foveal prestriate lesions. Physiology \& Behavior, 1972, 8, 177-181.

Masterton, R. B., \& Glendenning, K. K. Phylogeny of the vertebrate sensory systems. In R. B. Masterton (Ed.), Hand- 
book of behavioral neurobiology (Vol. 1): Sensory integration. New York: Plenum Press, 1978.

Nauta, W. J. H., \& Karten, H. J. A general profile of the vertebrate brain with sidelights on the ancestry of cerebral cortex. In F. O. Schmitt (Ed.), The neurosciences: Second study program. New York: Rockefeller University Press, 1970.

Nimi, K., \& Sprague, J. M. Thalamo-cortical organization of the visual system of the cat. Journal of Comparative Neurology, $1970,138,219-249$.

OrRego, F. The reptilian forebrain. I. The olfactory pathways and cortical areas in the turtle. Archives Italiennes de Biologie, $1961,99,425-445$.

Pasik, T., \& Pasik, P. The visual world of monkeys deprived of triate cortex: Effective stimulus parameters and the importance of the accessory optic system. Vision Research, 1971, 11, Supplement No. 3.

Peterson, E. Behavioral studies of telencephalic function in reptiles. In S.O.E. Ebberson (Ed.), Comparative neurology of the telencephalon. New York: Plenum Press, 1980.

PolyaK, S. The vertebrate visual system. Chicago: University of Chicago Press, 1957.

Powers, A. S. The role of the avian hyperstriatum in habit reversal (Doctoral dissertation, Bryn Mawr College, 1969). Dissertation Abstracts International, 1970, 30, 5721-B. (University Microfilms No. 70-10, 014)

Powers, A. S., Halasz, F., \& Williams, S. The effects of lesions in telencephalic visual areas of pigeons on dimensional shifting. Physiology \& Behavior, 1982, 29, 1099-1104.

Powers, A. S., \& Reiner, A. A stereotaxic atlas of the forebrain and midbrain of the eastern painted turtle (Chrysemys picta picta). Journal für Hirnforschung, 1980, 21, 125-159.
Reiner, A., \& Powers, A. S. The effects of lesions of telencephalic visual structures on visual discrimination performance in turtles (Chrysemys picta picta), in press.

Revzin, A. M. Some characteristics of wide-field units in the brain of the pigeon. Brain, Behavior, and Evolution, 1970, 3, 195-204.

Rothblat, L. A., \& Wilson, W. A., JR. Dimensional preferences with object and pattern stimuli in monkeys with inferotemporal lesions. Psychonomic Science, 1969, 17, 149-150.

Schade, A. F., \& Bitterman, M. E. Improvement in habit reversal as related to dimensional set. Journal of Comparative and Physiological Psychology, 1966, 62, 43-48.

Schneider, G. E. Two visual systems. Science, 1969, 163, 895-902.

Stetriner, L. J., \& Schultz, W. Brain lesions in birds: Effects on discrimination acquisition and reversal. Science, 1967, 155, 1689-1692.

Sprague, J. M., Levy, J., DiBerardino, A., \& Berlucchi, G. Visual cortical areas mediating form discrimination in the cat. Journal of Comparative Neurology, 1977, 172, 441-488.

\section{NOTE}

1. A table showing individual data on lesion size and behavioral performance on Problems 1, 3, and 6 is available from the authors upon request.

(Manuscript received January 12, 1983; revision accepted for publication April 6, 1983.) 